\title{
PENYULUHAN TENTANG SENAM LANSIA UNTUK MENINGKATKAN KUALITAS TIDUR PADA LANSIA POSYANDU SEHATI DESA PAUH MENANG
}

\author{
${ }^{1)}$ Reda Alfiani Lukmana, ${ }^{2)}$ Arif Pristianto, ${ }^{3)}$ Suparno \\ 1,2,3) Program Studi Profesi Fisioterapi, Fakultas Ilmu Kesehatan, Universitas Muhammadiyah Surakarta \\ J1. A. Yani, Mendungan, Pabelan, Kartasura - Sukoharjo - Indonesia \\ E-mail : 1)redaalfiani@gmail.com 2)arif.pristianto@ums.ac.id ${ }^{3)}$ parnoyoyok@gmail.com
}

\begin{abstract}
ABSTRAK
Lanjut usia adalah orang yang mengalami perubahan sistem biologisnya berdasarkan struktur maupun fungsi sehingga berpengaruh pada derajat kesehatannya. Seiring bertambahnya usia, lanjut usia tentu mengalami perubahan secara fisik, psikis, sosial serta spiritual. Penyebab perubahan tersebut dapat mengganggu kualitas tidur. Tingkat kemampuan fisik yang mengalami penurunan sangat berpengaruh pada kualitas tidur lansia. Tujuan dari pengabdian kepada komunitas lanjut usia adalah menginformasikan pentingnya menjaga kualitas kesehatan bagi lansia dengan ruitin melakukan senam lansia, sehingga lanjut usia dapat beraktifitas secara optimal. Evaluasi keberhasilan program dilihat dari berjalannya kegiatan senam secara rutin dari kelompok lansia dan menurunnya gangguan tidur lansia.
\end{abstract}

Kata Kunci: senam lansia, gangguan tidur, Pittsburgh Sleep Quality Index.

\section{ABSTRACT}

Older people are people whose the biological systems do a change structure and function to their status. As the age changes, older people are unwittingly subject to physical, psychosocial and spiritual changes. One of these changes is the quality of sleep. Declining physical ability also causes changes in the quality of sleep in the elderly. The aim of this program is to increase health quality for older people by regularly engaging in elderly gymnastics, thus allowing the elderly to mobilise optimally. Program success evaluations are seen by the regular progression of gymnastic activities from older groups and declining sleep disorders.

Keyword: elderly exercise, sleep disorders, Pittsburgh Sleep Quality Index

\section{PENDAHULUAN}

Penduduk dunia setiap detik mengalami kenaikan grafik usia lanjut dengan cepat. Hasil pengumpulan data sensus peduduk tahun 2010, Indonesia merupkan kategori negara dengan total penduduk lanjut usia terbanyak di dunia dengan 18,1 juta di tahun 2010, lalu 29,1 juta di tahun 2020 dan diduga hingga 36 juta saat tahun 2025. Peningkatan jumlah lanjut usia setiap tahun, tentu akan diikuti oleh peningkatan masalah lansia baik fisik bahkan psikis ${ }^{[1]}$.

Lanjut usia adalah orang dalam fase yang mengalami perubahan sistem biologisnya berdasarkan struktur maupun fungsi sehingga berpengaruh pada derajat kesehatannya. Pertambahan usia selalu ditandai dengan penurunan fungsi biologis yang terlihat dari kemampuan kognitif seperti mudah lupa, ingatan terhadap tempat, ruangan, dan waktu serta sulit menerima ide-ide baru yang terus berkembang ${ }^{[5]}$. Perubahan lain yang terlihat adalah fisik seperti tingkat kekencangan kulit, muncul keriput, warna rambut yang beruban, gigi menjadi ompong, penglihatan dan pendengaran berkurang, gerakan melamban dan mudah kelelahan serta terjadi penumpukan lemak terutama di pinggul dan perut ${ }^{[2]}$. Seiring bertambahnya usia, lanjut usia tentu mengalami perubahan secara fisik, psikis, sosial serta spiritual. Tingkat kemampuan fisik yang mengalami penurunan sangat berpengaruh pada kualitas tidur lanjut usia ${ }^{[1]}$.

Kualitas tidur adalah suatu kuantitas tidur individu dengan mudah terlelap dan nyaman 
untuk memberikan kebugaran dan kesegaran saat bangun dari tidurnya. Kualitas tidur dilihat dari aspek kuantitas, seperti durasi atau lamanya tidur, latensi atau kebiasaan sebelum tidur hingga terlelap serta aspek subjektif. Tingat kualitas tidur yang baik setiap orang harus mencapai tahapan tidur fase REM dan fase NREM ${ }^{[3]}$.

Tingkat kualitas tidur yang rendah sering dirasakan oleh lansia. Di Indonesia, prevalensi kualitas tidur yang rendah oleh lanjut usia sangat tinggi yaitu $67 \%{ }^{[4]}$. Lanjut usia yang memiliki tingkat kualitas tidur rendah jika tidak segera disembuhkan maka dapat memberikan banyak komplikasi, salah satunya adalah kebingungan saat siang hari, mengantuk dan resiko jatuh yang dapat menyebabkan fraktur ${ }^{6}$. Penurunan fungsi tubuh membuat lansia mudah lelah dan mudah terserang penyakit jika lansia tidak menjaga pola makan, pola tidur, bahkan pola aktivitas fisiknya.

Salah satu cara penanganan untuk meningkatkan kualitas tidur adalah dengan mengkonsumsi obat farmakologi, tetapi metode ini mempunyai efek samping, sehingga pengobatan non-farmasi sangat penting diberikan pada lanjut usia [7]. Pengobatan nonfarmakologi pada kualitas tidur usia lanjut bermanfaat untuk kesehatan secara umum dan mudah diakses dan dijangkau oleh sebagian besar usia lanjut adalah dengan melakukan senam aerobik [8]. Sebagai seorang Fisioterapis yang merupakan tenaga kesehatan dalam memberikan pelayanan kesehatan berhubungan dengan pengembalian gerak dan fungsi, perlu memperhatikan aktifitas fisik lansia terhadap kualitas tidur melalui Pittsburgh Sleep Quality Index.

\section{METODE PELAKSANAAN}

Pengabdian masyarakata yang dilakukan dalam komunitas lansia ini diselenggarakan dengan serangkaian kegiatan yang ditawarkan kepada komunitas lansia sebagai intervensi problem yang ada di posyandu lansia Sehati sekaligus meningkatkan pemberdayaan derajat kesehatan lansia. Beberapa kegiatan yang telah dilakukann sebagai berikut:

1. Penyuluhan kesehatan mengenai manfaat senam lansia terhadap peningkatan kualitas tidur lansia serta dapat meningkatkan pengetahuan kesehatan lansia dalam mencegah gangguan kesehatan.

2. Melakukan senam lansia di Gedung Olahraga dan Seni (GOS) desa Pauh Menang Kecamatan Pamenang dengan anggota posyandu lansia serta diikuti oleh pengurus posyandu. Kegiatan dilakukan dengan pemutaran video senam lanjut usia.

Kegiatan yang dilakukan diikuti seluruh pengurus dan anggot posyandu Sehati dan lansia sehingga gangguan tidur pada lansia dapat menurun dan aktivitas lansia dapat berjalan dengan baik.

\section{Kerangka Kerja Pengabdian}

Untuk mempermudah kegiatan pengabdian, maka penulis menyusun kerangka kerja kegiatan pada gambar 1.1: 


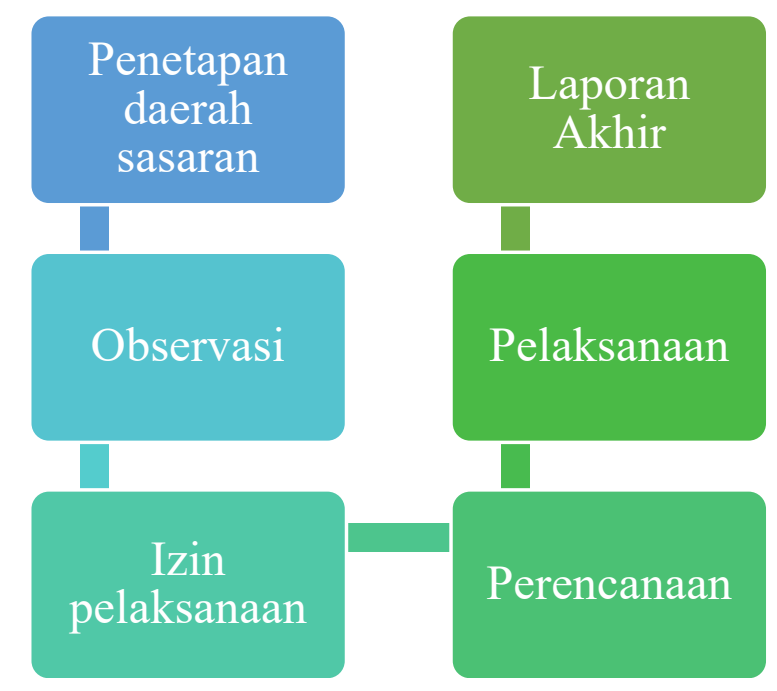

Gambar 1.1 Kerangka Kerja Kegiatan Pengabdian

\section{HASIL}

Kegiatan pengabdian masyarakat dilakuakan di posyandu Sehati Lansia desa Pauh Menang kecamatan Pamenang dengan serangkaian kegiatan.

\section{Penyuluhan Tentang Senam Lansia Untuk Meningkatkan Kualitas Tidur Pada Lansia Posyandu Sehati Desa Pauh Menang.}

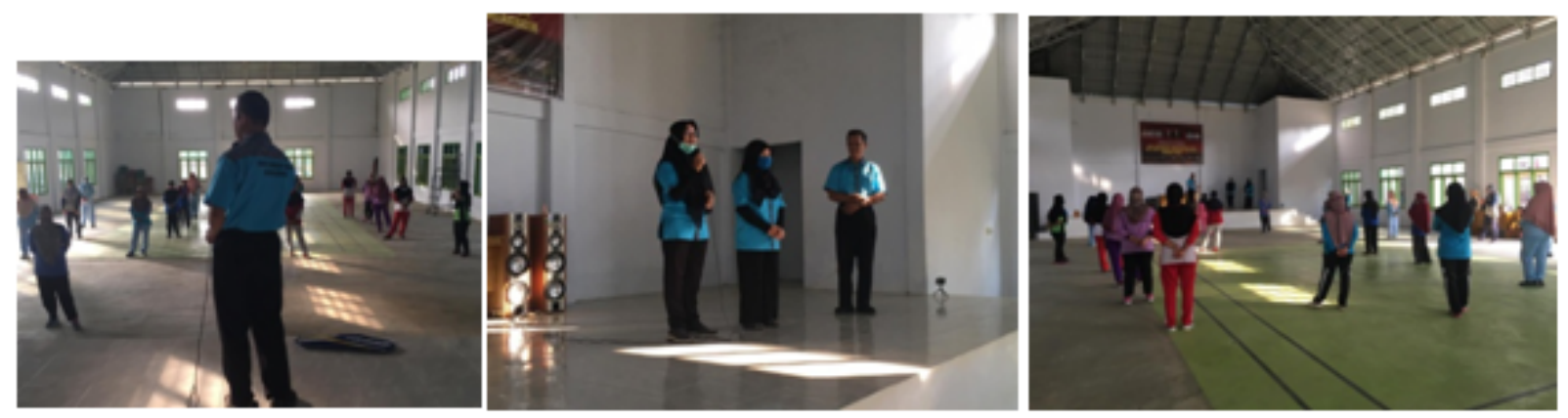

Gambar 2. Kegiatan penyampaian materi penyuluhan

Kegiatan pembuka yang dilaksanakan dalam pengabdian pada masyarakat ini adalah Penyuluhan Tentang Senam Lansia Untuk Meningkatkan Kualitas Tidur Pada Lansia Posyandu Sehati Desa Pauh Menang. Kegiatan terlaksana pada hari Minggu, 13 September pada pukul 07.30-08.00 WIB, bertempat di Gedung Olahraga dan Senin(GOS) desa Pauh Menang kecamatan Pamenang. Kegiatan ini dihadiri oleh pengurus kader posyandu Sehati lansia dan lansia berjumlah 12 orang yang bertujuan dalam meningkatkan pengetahuan dan pemahaman para lansia di Posyandu Sehati Desa Pauh Menang, Pamenang mengenai manfaat senam lansia terhadap tingkat kualitas tidur lanjut usia. Gangguan kualitas tidur lansia dapat mengganggu kebugaran da kesegaran tubuh lansia disiang hari, jika tidak segera ditangani atau dicegah dapat mengganggu aktivitas fungsional sehari-hari lansia. Sehingga kegiatan penyuluhan dilakukan mengingat banyaknya perubahan diberbagai organ yang dialami lanjut usia. 


\section{Pemeriksaan Tensi dan Pengisian Kuisioner Pittsburgh Sleep Quality Index.}

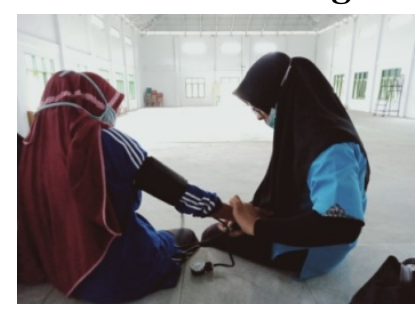

Gambar 3. Kegiatan Pemeriksaan Tensi dan Pengisian Kuisioner Pittsburgh Sleep Quality Index.

Kegiatan pemeriksaan tensi dan pengisian kuisiner PSQI merupakan kegiatan yang penting untuk dijadikan evaluasi kegiatan pengabdian masyarakat dalam memonitor pengaruh senam lansia terhadap kualitas tidur lansia. Kegiatan terlaksana setelah kegiatan penyuluhan kesehatan yaitu Minggu 13 September 2020. Peserta dalam kegiatan diikuti pengurus dan anggota lansia posyandu Sehati desa Pauh Menang. Kegiatan ini dilaksanakan bertempat di Gedung Olahraga dan Seni (GOS) desa Pauh Menang.

\section{Senam Lansia}
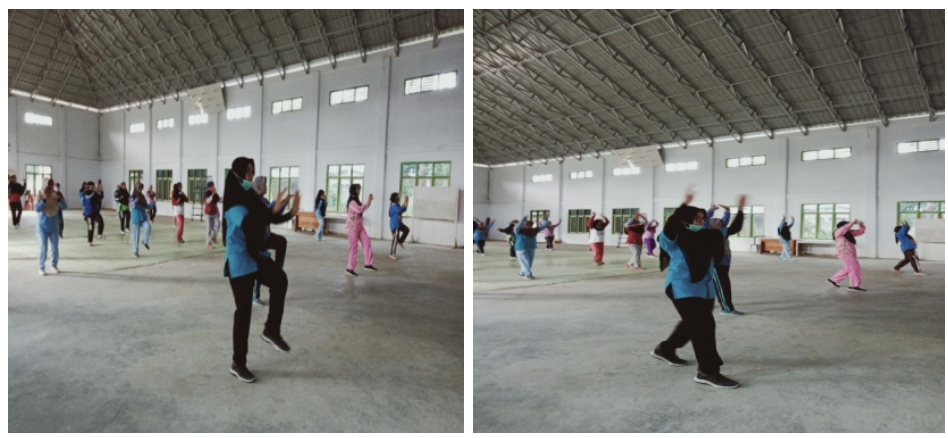

Gambar 4. Kegiatan Senam Lansia

Kegiatan senam lansia merupakan poin penting dalam membantu menyukseskan kegiatan. Kegiatan terlaksana setelah dilakukan pengisian kuisisoner PSQI yaitu Minggu 13 September 2020. Peserta dalam kegiatan diikuti pengurus dan anggota lansia posyandu Sehati desa Pauh Menang. Kegiatan ini dilaksanakan bertempat di Gedung Olahraga dan Seni (GOS) desa Pauh Menang.

Tabel pengolahan data

Tabel 1. Tabel Pengolahan Data

\begin{tabular}{rlllrl}
\hline \multirow{2}{*}{ No } & Nama & \multicolumn{2}{c}{ Pre } & \multicolumn{2}{c}{ Post } \\
\cline { 3 - 6 } & & Skor & Ket & Skor & Ket \\
\hline 1 & Lansia 1 & 11 & Sedang & 8 & Sedang \\
\hline 2 & Lansia 2 & 13 & Sedang & 6 & Sedang \\
\hline 3 & Lansia 3 & 9 & Sedang & 6 & Ringan \\
\hline 4 & Lansia 4 & 12 & Sedang & 8 & Sedang \\
\hline 5 & Lansia 5 & 15 & Buruk & 13 & Sedang
\end{tabular}




\begin{tabular}{ccclcc}
\hline 6 & Lansia 6 & 13 & Sedang & 8 & Sedang \\
\hline 7 & Lansia 7 & 12 & Sedang & 9 & Sedang \\
\hline 8 & Lansia 8 & 15 & Buruk & 12 & Sedang \\
\hline 9 & Lansia 9 & 11 & Sedang & 7 & Ringan \\
\hline 10 & Lansia 10 & 6 & Ringan & 5 & Ringan \\
\hline 11 & Lansia 11 & 11 & Sedang & 7 & Ringan \\
\hline 12 & Lansia 12 & 16 & Buruk & 10 & Sedang \\
\hline
\end{tabular}

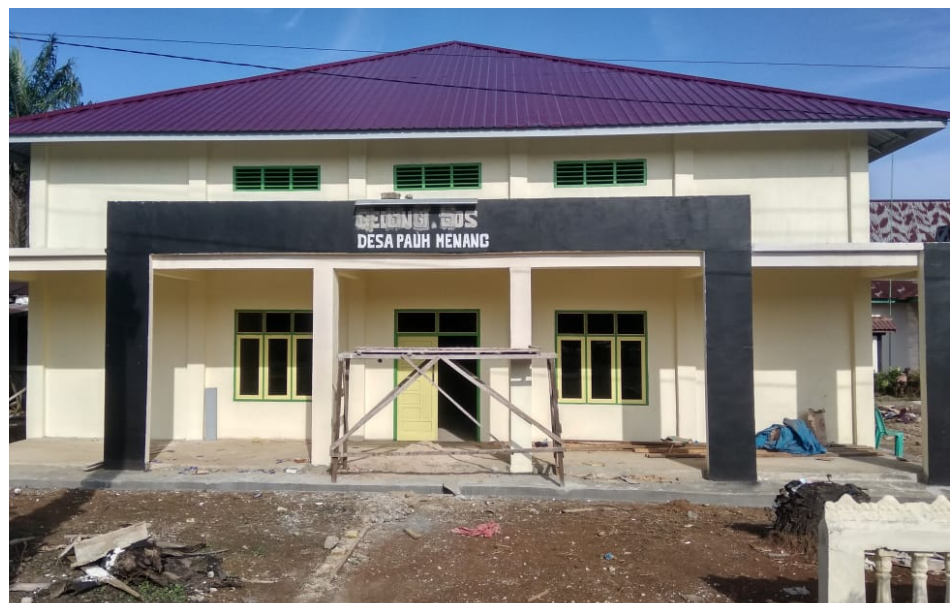

Gambar 4. Lokasi kegiatan

Kegiatan pengabdian masyarakat dilakukan pada tanggal 13 September 2020 di Gedung Olahraga dan Seni (GOS) desa Pauh Menang. Lokasi GOS berada di selatan kantor desa Pauh Menang.

\section{KESIMPULAN}

Penurunan kondisi pada lansia terajadi di usia 40-80 tahun, perubahan yang terjadi berdasarkan fisiologis maupun psikologis. Perubahan tersebut memiliki pengaruh dalam menjaga kualitas tidur lansia. Jika lansia mempunyai gangguan kualitas tidur maka dapat menganggu aktivitas fungsional sehari-hari. Usaha untuk menjaga kesehatan lansia baik dalam perawatan, pengobatan dan pola hidup sehat diantaranya adalah senam lansia.

\section{DAFTAR PUSTAKA}

[1] Al-Amin, M., \& Juniati, D. (2017). Klasifikasi Kelompok Umur Manusia Berdasarkan Analisis Dimensi Fraktal Box Counting Dari Citra Wajah Dengan Deteksi Tepi Canny. J. Ilm. Mat., vol. 2, no. 6, pp. 1-10.

[2] Tumaloto, E. (2019). Pengembangan dan Pendampingan Senam Lansia di Masyarakat Dungalio Kabupaten Gorontalo. Respiratory.ung.ac.id.

[3] Saryono \& Widianti, A.T. (2010). Catatan Kuliah Kebutuhan Dasar Manusia. Yogyakarta: Nuha Medika.

[4] Amir, N. (2007). Gangguan Tidur pada Usia Lanjut. CDK. 157:199 
[5] Araújo, C.L. \& Ceolim, M.F. (2010). Sleep Quality of Elders Living in Long-term Care Institutions', Artigo Original, 44(3), pp. 619-626.

[6] McPhee, J.S., French, D.P., Jackson, D., Nazroo, J., Pendleton, N., \& Degens, H. (2016). Physical Activity in Older Age: Perspectives for Healthy Ageing and Frailty. Biogerontology, 17(3), 567-580. https://doi.org/10.1007/s10522-016-9641-0

[7] Monica, R., \& Nasution, N. (2017). Pengaruh Latihan Fisik Intensitas Ringan dan Sedang terhadap Perubahan Kadar Hormon Beta - Endorphin Mencit (Mus Musculus L .) Hamil. Biomedical Journal of Indonesia, 3(2), 91-98.

[8] Brupbacher, G., Straus, D., Porschke, H., Zander-Schellenberg, T., Gerber, M., Von Känel, R., \& Schmidt-Trucksäss, A. (2019). The Acute Effects of Aerobic Exercise on Sleep in Patients with Depression: Study Protocol for a Randomized Controlled Trial. Trials, 20(1), 1-18. 